Article

\title{
Rearranging Differential Inclusion through Civic Solidarity: Loose Coupling in Mentorship for "Unaccompanied Minors"
}

\author{
Eberhard Raithelhuber \\ Department of Educational Science, University of Salzburg, 5020 Salzburg, Austria; E-Mail: eberhard.raithelhuber@gmx.at
}

Submitted: 15 January 2019 | Accepted: 15 March 2019 | Published: 27 June 2019

\begin{abstract}
This article looks into a community-based mentoring programme for unaccompanied refugee minors (URMs), launched in 2015 at the peak of refugee movement in Austria. Leaning on a long-term ethnographic study, it sheds light on dynamic developments in refugee support through civic solidarity. The article proposes that examining the programme from the point of view of dialectic processes of organizing provides a better standpoint for asking what was produced on the programme and what influences those outcomes have had on more contentious political dimensions. Following this, the focus is concentrated on "loose coupling" within a pilot youth mentoring scheme. This reveals how inbuilt ambiguities were given structure, how rationality and indetermination were interdependently organized and how the uncertain was ascertained through mentor training and matching. Thus, unequal but personal relationships were brought about and stabilized. The particular institutionalization of "godparenthoods for URMs" offered possible ways of integrating various elements of a support system in a way which could provide better support than other relationships amongst strangers. I argue that these specific forms of loose coupling opened up a corridor in which aspects relating to the differential inclusion of young refugees were (re-)arranged through adults volunteering, but with mixed results.
\end{abstract}

\section{Keywords}

child and youth welfare; civic solidarity; loose coupling; organizational ethnography; refugee support; unaccompanied refugee minors; volunteering; youth mentoring

\section{Issue}

This article is part of the issue "The European Refugee Controversy: Civil Solidarity, Cultural Imaginaries and Political Change", edited by Gert Verschraegen (University of Antwerp, Belgium) and Robin Vandevoordt (University of Oxford, UK/University of Antwerp, Belgium).

(C) 2019 by the author; licensee Cogitatio (Lisbon, Portugal). This article is licensed under a Creative Commons Attribution 4.0 International License (CC BY).

\section{Introduction}

Some years after the arrival of up to ten thousand refugees a day in the "long summer of migration" in Europe in 2015, academia is asking what traces of this remain. As proven by this thematic issue of Social Inclusion, more and more scientists are inquiring into the extent to which civil initiatives have translated into institutional developments and change in the social sector (e.g., Feischmidt, Pries, \& Cantat, 2019; Lace, 2018). Some are taking stock of the potential impact of these developments by considering if, and how, civic solidarity has altered or extended forms of social support and care within the welfare state. The present article follows this trend but pursues two aims. Firstly, it provides empirical find- ings on a community-based pilot mentoring programme for unaccompanied refugee minors (URMs). Secondly, and inseparably from this, I offer an example of how a perspective on "loose coupling" can be fruitfully applied in research on civic support initiatives.

To pursue the double objective, on one hand I look into substantial results from a case study on the abovementioned youth mentoring scheme, which launched in 2015 in an Austrian region. Drawing on the results of this overall investigation, I make the case that this form of civic solidarity and volunteering has indeed added to established, professional and institutionalized welfarist social support and care. All of this has to some extent rearranged the differential inclusion of these young people, though with mixed results. For example, the godpar- 
enthood programme did not change fundamentally how political representatives and agencies that are funded or run by the state handle the situation of these young people institutionally. However, as I will show, this model of organizing civic solidarity has continuously supported the young participants in navigating their life courses. It has extended and intensified the various support measures that the ombuds-organization piloting the mentoring scheme provides for young refugees.

This article's other objective is to move beyond established ways of mapping and assessing the results of research on civic solidarity. Our ethnographic approach allowed a number of questions to arise and then crystallize over time as the complex research project unfolded: how could the dispersed social realities and activities of organizing we came across be so crudely represented and even rebranded as "godparenthood for URMs"? How could this programme, launched at the peak of refugee movement and acts of solidarity, still be "successful" despite the radical right-wing policies developing in Austria? Within our study, such contemplative, but fundamental questions called for a middlerange theory or concept to shape and make sense of the research we conducted: loose coupling (Orton \& Weick, 1990; Wolff, 2010). Applying that concept to data from a long-term qualitative case study, I show how we can assess in a sophisticated way what has been produced and has become organizable and producible within refugee support initiatives with regard to more contentious, political dimensions. Therefore, I provide an example of applying a heuristic that may also be helpful to address related issues in future research.

Taking the twofold objectives together, the overall intention of this article is to discuss findings from an indepth case study under the conceptual perspective of loose coupling to advance academic discussion in the field. Thus, based on the relational understanding of the author, the article does not want to get rid of complexity, but to unfold it by connecting dynamic and dialectic aspects within the overall study. This will allow for demonstrating how ambiguities and uncertainties in systems which are typical for momentums with a change potential were both brought about and dealt with. In the given case, this allows for understanding how all of this led to a particular outcome: the "success" and even sustainability of the programme "godparenthoods for URMs", bearing on civic support for refugees.

In the following, I start by describing the local context and theoretical background for the latter empirical focus. This involves outlining the development of the mentoring programme and connecting it to the social positioning of URMs in public care in Austria. Leaning on political theory, I regard the situation of URMs as one that is characterized by "differential inclusion" (Mezzadra \& Neilson, 2012). Then I introduce the key principles of a loose coupling perspective in organizational research. As this approach is not widely used in scientific reasoning on the rise and development of civic support initiatives for refugees, I elaborate on the fundaments of "loose coupling theory" (Orton \& Weick, 1990). Together with a brief look at methods and data, this serves as a prelude to the core of this article: the conceptually inspired integration and discussion of findings from the overall in-depth case study from the perspective of loose coupling. To this end, in the main section I will show how the mentoring scheme under observation made it possible to rearrange various aspects of this differential inclusion of URMs. Towards the end, I determine six core aspects which can be uncovered through this organizational perspective on a local refugee support initiative, before adding a political assessment and outlook on future research and practice.

\section{The Mentoring Programme and the Differential Inclusion of Minor Refugees}

In the summer of 2015, an acknowledged, semiindependent regional ombuds-organization for children and youth announced the implementation of a new mentoring scheme for URMs, calling for volunteers. This mirrored developments in other parts of Austria (see Scheibelhofer, 2019). Shortly thereafter, around a hundred local people took part in the first information evening. Dozens declared their interest in becoming a "godparent" ("Pate" in German). The plan was to turn some "godparenthoods" ("Patenschaften") into "host families" ("Gastfamilien", not to be confused with foster families). According to this plan, a handful of URM mentees would move into the mentors' households, having already established firm mentoring relationships. Shortly after the kick-off evening, ombuds-agency staff started the first compulsory training cycle with local adult volunteers, consisting of around 20 hours of preparation, accompanied by personal assessments and consultations.

Meanwhile, trains packed with refugees crossed into Austria on their way to Germany and beyond. As a result, the ombuds-organization launched the programme ahead of time, due to the pressure felt and the enthusiastic response from civil society. When the first mentors were trained and ready, staff went to the special accommodation units housing most URMs between 14 and 18 years of age, explaining how mentoring works and what it achieves. Many declared their willingness to "get" a mentor. The new mentors then got to know "their" young refugees at an assisted face-to-face meeting, known as "matching". After this, they met regularly on their own with no set end date. In the background, the agency continued its activities. At the end of 2018, nearly 200 mentors had been trained and more than one hundred "godparenthoods" were still active, far beyond what the agency had defined as a minimum target.

\subsection{Contextualizing "Unaccompanied Minor Aliens" in Austria}

This picture-book story calls for context. From 2014 to 2018 , more than 16,000 young refugees claimed asy- 
lum as minors in Austria (population: approx. 9 million), with a peak of around 8,000 applications in 2015. Over $90 \%$ were male and an equal number gave their age as between 14 and 18 . The vast majority of these URMs were considered to have Afghan citizenship, while a sizeable group also described Syria and Somalia as their native countries, followed by other countries of the Maghreb, Central and West Africa and the Middle East. Beyond this basic statistical information, there is almost no research-based scientific knowledge on the lived experience and institutional handling of URMs in Austria. In addition, there is still no full official portrayal of the different systems and services around the legal representation of URMs and their accommodation in public care (Heilemann, 2017). The Austrian office of the International Organisation of Migration (IOM) and UNHCR Austria have now issued detailed publications which fill some of these gaps (see Bassermann \& Spiegelfeld, 2018; UNHCR, 2018). This deplorable situation is one reason behind the disparate ways in which institutions deal practically with URMs across the country. For example, there is no particular agreement on the minimum standards for the legal representation of URMs during their asylum procedure. Detailed rules for this are generally lacking, including on the level of the federal provinces (the nine Länder), which play a key role in the federal Republic of Austria. Moreover, the recent turn towards extreme right-wing policies in Austria has caused a constant shift in conditions and infrastructures in the refugee management and asylum systems (for more details see Merhaut \& Stern, 2018).

However, some basic structures for URMs can be mapped. As a rule of thumb, if a person claims asylum in Austria, he or she falls into the basic welfare support scheme for refugees ("Grundversorgung"), grounded in the Federal Basic Welfare Support Act. Basic welfare support is generally applied to all asylum claimants and to refugees without a "first-class" asylum status. URMs are dealt with under this scheme until they get a positive asylum decision or leave the country. Generally, as soon as refugees enter the national asylum procedure, they fall under the responsibility of one of the Länder (Ganner, Jicha, \& Weber, 2016, pp. 23-24.). Most unaccompanied minor "aliens" ("Fremde", a legal term) aged between 14 and 18 who are sent to the Länder are not housed in regular out-of-home child and youth care. Instead, they are accommodated in special residential facilities for youth under the basic welfare support scheme. These mass accommodation units, as I call them here, are part of the refugee management system and administration, and are very dissimilar in nature across the country. The public child and youth welfare authorities take on legal guardianship for URMs residing in the country without a "natural" guardian, e.g., parent or adult kin. However, these legal guardians, often state-employed social workers, generally do not, and cannot, operate as independent, powerful and resourceful representatives of these children. In practice, their duties, e.g., care, edu- cation and counselling, are largely delegated to providers contracted to run mass accommodation units for URMs, working under inadequate conditions.

In contrast to adults, minors in basic welfare support at least can and should receive additional support according to the law, e.g., regarding schooling or child and youth services. However, various legal opinion-makers deplore the fact that the state authorities and contractors providing basic welfare support for URMs have a broad discretionary power regarding the provision of these additional support measures (e.g., Ganner et al., 2016). Generally, URMs can only transfer to regular outof-home youth care institutions after they are granted full asylum and before reaching the age of majority. Only a minority have qualified. However, if URMs can enter regular out-of-home child and youth care, they have much better de facto access to social services and support and possibly even receive that support for a longer time, before they definitely have to leave care when turning 21. Simply put, Austria has already had a two-class system in public care for a long time: on the one hand "regular" out-of-home care in child and youth welfare (group homes, semi-independent housing or foster families) and on the other hand "irregular" care for URMs without full asylum status housed in special accommodation units. Most URMs are in the latter group. In terms of volume, in the state where the mentoring project operated, the number of URMs (age 14 to 17 ) receiving basic welfare support in mass accommodation in 2015 surpassed the number of children, youth and young adults in "regular" out-of-home care (age 0 to under 21).

In brief, mass accommodation units for URMs have much less favourable conditions for what is commonly referred to as "integration" into the receiving nation/state/society. The above-mentioned recent IOM report on URMs in Austria concludes:

On the whole, the transition to adulthood is seen as a challenge....Austria has no specific nationwide measures in the areas of care and integration that are designed to prepare unaccompanied minors for the transition to adulthood.... (Bassermann \& Spiegelfeld, 2018, pp. 33-34)

Many newcomers only have access to public schools or other welfare services under precarious conditions. This is despite the fact that Austria ratified the universalistic UN Convention on the Rights of the Child (UN CRC). However, the unjust legal and social treatment of URMs in Austria is "legitimated" and practised by the official administrative bodies, first and foremost by youth welfare authorities which do not actually take in URMs. In contrast to this, legal opinions and reports by ombudsman boards have stated repeatedly that child and youth welfare has to guarantee the provision of adequate services to all young people in need (Die Kinder- und Jugendanwaltschaften, 2015). To sum up, this situation can be understood as the differential inclusion of URMs into var- 
ious institutions and organizational systems of the Austrian nation state and society, most notably in care, education and health.

\subsection{The Concept of Differential Inclusion}

By characterizing the inclusion of URMs as differential, I adopt a concept which has become popular in critical migration and border studies, but is equally rooted in anti-racist, cultural and feminist studies (De Genova, Mezzadra, \& Pickles, 2014, p. 25). Up to now, it has rarely been applied in studies on social policy and social services. "Differential inclusion" reflects insights from a political theory of immigration and citizenship (see Anderson, 2013). It starts from the assumption that society is pervaded by and made up of multiple bordering processes. They shape all kinds of positions of membership, subjectivities and belonging, going deeply into the political space (Balibar, 2003). In the context of this article, the concept serves to grasp the complex and confusing ways in which young people who are categorized as URMs are unequally woven into the social fabric in concrete terms, in the context of the refugee management system and youth welfare.

Describing migrants as undergoing differential inclusion highlights the fact that borders are permeable and that different political figures (see Nail, 2015) are subject to and created through different regimes of mobility (Glick Schiller \& Salazar, 2013). Hence, the ways such othered subjects are categorized, valued, selected and, finally, excluded and included are dynamic, and undergo occasional processes of (re)negotiation:

The nub of the matter, however, is how these differential processes of bordering affect the threshold that lies between governmental processes of delivering justice and the politics of claims that exceed them....There is a need to further investigate the processes and discontinuities that characterize the relation between the variations of this threshold and the contemporary transformations of borders. (Mezzadra \& Neilson, 2012, p. 197)

In my work, I endorse these thoughts expressed by core proponents of the perspective in multiple ways. First, in the context of my broader aims I take their lead in formulating a research framework that allows me to examine the intersection of social (de)protection and (im)mobilities (Raithelhuber, Sharma, \& Schröer, 2018). Second, in the case study on the programme behind this article, "godparenthoods for URMs", I consider the establishment and lived realities of youth mentorship as this type of threshold of negotiation and, possibly, site of contest. The present article narrows down the focus by adopting a theoretically informed position that understands youth mentoring for URMs by adult volunteers from civil society as one potential site for negotiating and, possibly, for reshaping aspects of differential inclusion.
Up to now, no study has looked into such processes from the organizational perspective of loose coupling.

\subsection{Research Gaps and Lacking Focuses}

In my understanding, examining differential inclusion requires sensitivity to discontinuity and processes, rather than making continuity and structure (in the sense of stability) the starting point for empirical analysis. This makes a pilot youth mentoring scheme based on civic solidarity for refugees an interesting starting point for observations, as it allows a number of questions to be asked. What actually comes true when an ombuds-organization founded on the universalistic principles of the UN CRC engages in a new social support scheme for URMs outside official youth welfare, but built on civic engagement? What kind of institutional and biographical work is done? How does a pilot programme deal with upcoming uncertainties and insecurities?

Such questions call for a perspective that is yet to be established in research on (youth) mentoring. Mainstream mentoring research, which mainly uses quantitative methods, adopts an operational and factorial perspective, e.g., looking at mentors' attributes, contextual factors, (self-)assessments, and "add-ins" (i.e., mentor training, matching, screening, etc.). Many studies seem aimed at developing knowledge on success in programmes, including programmes for "immigrants and refugee youth" (Birman \& Morland, 2014) or young people in public care (e.g., Sulimani-Aidan, Melkman, \& Hellman, 2019). Put simply, most studies in the field follow an individualistic, positivistic and evidence-based logic (for an exception see Schott-Leser, 2018). Qualitative research on youth mentoring through stand-alone programmes (in which a mentor-mentee dyad is intentionally created) is still scant (but see Colley, 2003). That applies all the more to research on community-based mentoring schemes for youth. What is more, there is still little critical discussion of methods and methodology in qualitative research on mentoring, including discussion on organizational aspects.

In brief, in contrast to mainstream research which focusses on youth mentoring (e.g., Behnia, 2007; Lakind, Atkins, \& Eddy, 2015; Larsson, Pettersson, Eriksson, \& Skoog, 2016), I conducted research within or in the midst of mentoring. In other words, youth mentoring was not the primary object of desire. Fairly more, for me it was a provisional empirical anchor to engage with the highly stratified, complex and dynamic orderliness of social life, and with perceived changes to that orderliness. Here, this is achieved by applying an organizational perspective of loose coupling to "godparenthoods for URMs", anchored in a civic solidarity initiative.

\section{Context of the Study, Methods and Data Analysis}

The study was part of an explorative and qualitative investigation that started in the summer of 2015 (Raithel- 
huber, 2018). It began in haste at a time when events were coming thick and fast. The team was led by a principal investigator, the author of this article, and four young female voluntary researchers, some of them university students. Initially, the agency which started the new scheme called upon the author to do an evaluation. However, I decided to take a much more fundamental research stance, enabling the team to draft an internal research report (given to the agency) and at the same time offering an academic outcome. Given the unsatisfactory scientific knowledge on mentorship programmes for URMs, and on URMs in Austria in particular (see above), we asked a simple but fundamental question: What "on earth" is happening here?

Building on my experience as an ethnographer, the overall research project that I employ as an example embraced alienation and an initial lack of "cultural" understanding as core approaches for data collection and analysis. The case study mainly looked into three different aspects of the mentoring project: first, the public events to attract future mentors and the subsequent compulsory training of adult volunteers (participant observation, e.g., on a full training cycle); second, sense-making by these mentors (initial and several follow-up narrative interviews, N1 = 18; N2 = 13); and third, the perspective of the young mentees (two multi-lingual one-time group interviews, embedded in socio-cultural events, N1 = 10, $\mathrm{N} 2=8$, all male; languages used: Somali, Arab, Dari/Farsi and German). Besides this, photos were taken of events or places connected to the pilot scheme, artefacts were collected (e.g., forms used by the ombuds-agency, reports, handouts), and representations were examined on social media and in the press. The particular research settings, methods and methodology of the substudies have been presented elsewhere (Raithelhuber, 2018, 2019a). Here, it shall suffice to say that ethnographic and narrative data was produced over more than three years, without noteworthy funding from third parties. The analysis of field notes (Emerson, Fretz, \& Shaw, 2011) was inspired by membership categorization analysis (Fitzgerald \& Housley, 2015). We mainly used content analysis for the initial interviews with prospective mentors, as well as for the one-time group interviews with youth, enhanced by aspects of in-depth sequential text analysis. The documentary method (Nohl, 2010) has been employed to analyse follow-up interviews with experienced "godparents". This part of the long-term qualitative substudy is still continuing.

Participation in the interviews was voluntary. Data collection, including during the training cycle, was based upon informed consent. In the group interviews with the young refugees we deliberately did not ask them about their experiences during or before their flight. In contrast, we concentrated on their experiences with their match and with the ombuds-organization. The quotes in the following section are all translations from German and Austrian German. All names of persons, places and organizations were anonymized in this article.
The particular perspective of loose coupling that I bring to the fore in this article emerged at an early stage of the analysis. The concept helped us to understand the ethnographic material on the mentor training, which initially seemed to be divergent and confusing. In the context of this article, loose coupling is employed as a heuristic to integrate and discuss particular findings from the overall study from the perspective of loose coupling.

\section{4. "Loose Coupling Theory" and Human Service Organizations}

In an overview of developments, Meyer (2017, p. 430) stated that since the 1990s "organizational theory has focused not on entities as unitary structures, but on complexity and differentiation in organizations and in their environments". The perspective of loose coupling I invoke here deals with related issues. It concentrates on processes within systems and on interactions between elements, rather than on properties of particular elements per se (Czarniawska, 2006, p. 1661). In the present article, I follow Orton and Weick's (1990, p. 218) proposition of seeing "the concept of loose coupling...as a useful tool in identifying, measuring, and understanding interpretative systems". I consider the pilot youth mentoring project under scrutiny to be such a system.

\subsection{Keystones of a Loose Coupling Perspective}

Loose coupling pioneers assume that systems can evolve which are both loose and coupled at the same time (Orton \& Weick, 1990; Weick, 1976). Their relational, dynamic and dialectical perspective, in particular, opens up a unique way of understanding how organizing (i.e., processes of structuring) and the constructions making up a system are possible in the light of ambiguity and uncertainty (for an overview, see Wolff, 2010, pp. 286-295). In organizational parlance, this approach is able to grasp the fact that particular elements or parts of (some) systems can maintain a degree of independence and indeterminacy, thus conducing to heterogeneity within a system. At the same time, some elements and their relationship are determined. Taken together, different elements respond to other elements within the systems (and, thus, do not act fully independently). As a result of this particular interdependency, rationality and indeterminacy combine in ways that enable systems to achieve distinctive capacities and performances (Orton \& Weick, 1990, pp. 205-208). This aspect is important for the way in which I will present and discuss findings. One reason for choosing the perspective of loose coupling is that the regional ombuds-organization for children and youth which developed and implements the mentoring scheme shares features of a human service organization (HSOs). HSOs display strong characteristics of loose coupling, for which internal fragmentation is one cause. 


\subsection{The Advantage of a Loose Coupling Perspective on "Civic Solidarity for Refugees"}

Research on situations with the potential for changee.g., those discursively defined as "crisis", "emergency" and "exceptional"-requires an approach that is sensitive to uncertainty and ambiguity. This supports the choice of a "loose coupling" perspective in order to analyse emerging civic solidarity for refugees. A recent study looked into experiences in mentorships or "sponsorships" for URMs in the Austrian context as a form of "intimate solidarity" (Scheibelhofer, 2019). It highlighted important topics in mentors' experiences of relationships in "godparenthoods", e.g., the intersection of emotions, gender, and care in civic engagement. Though the research results reveal ambivalences, they do not feature a thoroughly organizational perspective. Organizational perspectives have been employed to look into how HSOs deal with URMs, though on a small scale. For example, a micro-analytic study in this field that focuses on cultural images of URMs uses sociological neo-institutionalism as a prism (von Oppen, 2018). However, von Oppen solely investigated "professional" social work with URMs, thus not examining civic solidarity.

It is notable that the loose coupling perspective does not start out from a reified picture in which "organization" is considered to be an ordered and rational entityor even a single entity at all. In contrast, it focuses on the structuring and processing of events and relationships. Below, I use this approach heuristically to map substantial findings on a particular case of civic solidarity initiative for refugees under the conceptual perspective of loose coupling.

\section{Findings}

I start by thrusting you into the raw data, a field note from the public event launching the youth mentoring programme for URMs. The head of the ombudsorganization, overwhelmed by the high number of interested adults from civil society, explained this new scheme as follows:

[Head] says that the [ombuds-organization for children] put their "heart and soul into children's rights" and that in these circumstances, the children's rights of refugee minors are being violated, by the standards of care....Word for word: "No child may be discriminated against; all children are equal". The children need special protection and support, precisely because they are vulnerable, says [head]. "Specially adapted to URMs because of the difference in the task, expectations and background conditions". He/she also refers to the UN CRC in that context. In 2015 the focus is supposed to be on structural improvements to the background situation for URMs. The aim is to achieve equality between URMs and Austrian children and adolescents. The former, [head] contin- ues [stretching out and emphasising "former"] has a long way to go....The latter [again, he/she stresses the word] is, however, something very concrete; direct help. (Field notes from information event)

How can we read this? On the surface, the agency's actions in dealing with discrimination against URMs as publicly stated here by the agency could be described as diverging and even inconsistent (see Wolff, 2010, p. 307). However, the chosen perspective of loose coupling does not regard the development of community-based mentoring for discriminated URMs as a poor solution to a supposedly given social problem. Instead, it suggests that such a "decision" is part of an (active) search for a problem in the light of already ongoing actions and changes. In developing mentoring, organizations actively both deal with and produce uncertainty and ambiguity. In the following paragraphs, I will unfold six key examples of how ambiguities and uncertainties were both dealt with and brought about in related processes of organizing youth mentoring for URMs.

\subsection{Proclaiming that Diverging Decisions Are Natural to Various Audiences}

In 2015, the ombuds-agency had been running a general mentoring programme for children and youth for several years, characterized by the individualized training and matching of volunteers. Besides up to 200 "local" children and youth, it had also integrated a handful of teenagers who originally came to town as URMs. Connected to this and according to the founding myth of "godparenthoods for URMs" within the agency, it all started out with a growing awareness that voluntary mentors needed different knowledge to deal with the challenges they face when engaging into a personal relationship with an URM. A staff member remembers how he/she felt when these adult volunteers from the established general youth mentoring programme addressed them:

Yes, they really sat there, and I thought, they're all asking the same questions. Makes sense. They all have the same issues. What's the [asylum] interview? What does he [the mentee] talk about, then? Yes, or, is there anything I can do wrong? And so we said, of course, it would really be good if we can give them [the mentors] something in advance, you know, tell them what it actually means to undergo an asylum procedure. That's generally something we don't have a clue about, right? And so that's how it came about. (Interview with ombuds-agency worker A)

A hypothetical option to react to such perceived needs would have been to add to the general programme, which the organization itself presented as well developed. However, the agency "opted" to develop a particular new programme aimed at attracting, screening, training, matching and-later on-supervising "godpar- 
ents for URMs". Hence, in my view, this move from "mentoring" to "godparenting" was conditional on a different type of sense-making: a handful of cases were explored by applying particular knowledge, leading to a (re)framing of these mentees as URMs. At the same time, the agency put the ill-treatment of URMs (see Section 2) on its nationally coordinated agenda-a fact that resounds in our note on the information evening above. Hence, a number of activities were already going on, actually since the Millennium. Both things togetheri.e., first the reassessment of existing mentoring relationships as requiring different knowledge on the part of adult volunteers (and, incidentally, the agency itself) and, second, ongoing activities related to URMslater allowed the new scheme to be depicted as a selfevident necessity and decision, fully coherent with the agency's universalistic mission. This switch to a new, now partly pedagogically framed social problem agenda by the ombuds-organization was achieved by connecting it to both publically and professionally widely shared sociocultural representations of the "unaccompanied refugee minor" (Raithelhuber, 2018, 2019a). Hence, "URMs" could be charted as a particular social problem, as well as a "solution" to them being proposed: community-based mentoring for URMs.

To sum up, in organizational language, a "discovery" of this kind enabled the organization to rationalize particular actions, some of which had already been realized and are continuing. The proclamation of the new scheme can be seen as part of a constitutive process to account for a variety of actions towards internal audiences (e.g., colleagues) and external audiences (e.g., civil society, NGOs in the refugee management system). This explanation enabled the (re-)allocation of particular resources within the ombuds-agency, e.g., the deployment of more than two full-time staff members. It facilitated the integration of a new, exceptional space-a lab-into existing activities in a cautious way: one that did not put the overall operability of the agency at risk. By searching (for) their new problem, parts of the ombudsman organization switched from a routine mode into a developmental mode. This allowed enhanced institutional work on uncertainty to be carried out. One aspect of this was that the agency proclaimed diverging decisions as something natural and rational to various audiences. This sense-making of the situation as a sort of incubator was not linked in any particular way to migration or refuge, however. Templates were found in the organizational (self-)narrative. That narrative takes material form at the agency in a huge silver timeline made of cardboard boxes. This symbolic agency lifeline, as I would call it, marks previous catalytic periods, including their completion (e.g., their transformation to youth welfare legislation). At the same time, a new term was invented for the voluntary mentors for URMs: "godparents". What is more, the name given to the programme conveys the idea of an intimate, warm-hearted and caring personal engagement, letting or taking someone in.

\subsection{Ascertaining the Uncertain and Determining the Indeterminable through Training Prospective Mentors}

Dependency on external resources, e.g., public funding, is typical for HSOs (Hasenfeld, 2009). What is more, any community-based mentoring programme depends on the integration of resources from civil society. From this perspective, the public communication of a decision to start mentoring for this particular group also provided the legitimation to connect external resources to mentoring activities, i.e., local adult volunteers. This, however, needed to be done in a way that both preserved and altered volunteers' borders and identities. One core means of bringing about this as well as the (re-)alignment of various actors was the establishment of a training curriculum. The complexity of an uncharted mentoring relationship with a social neophyte who-according to the ombuds-agency-was subject to severe discrimination and, in addition, a "minor", was reduced to topics which were held to be essential for dealing with young people as URMs (e.g., intercultural communication, asylum law, housing situation and everyday life, dealing with trauma). Staff literally referred to these aspects as a sort of "basic vocabulary".

For example, during training, URMs were characterized as generally traumatized, and this trauma was presented as something that could break out at any given time. Mentors were informed that this normally calls for psychotherapy, but that there was no such professional treatment available for URMs. In this context, the role of mentors was pictured as one of simply "being there"-something I reconstructed elsewhere as an element of one of three godparent figures: the "professional godparent", tending towards a "joker professional" or "surrogate professional" (Raithelhuber, 2018). In our interviews with prospective mentors (i.e., before they actually met their future match), volunteers described this "being there" for the young refugees as their selfunderstanding. Far from defining a simple and clear task, this construct of "simply being there" is reflected in the following quotes from initial interviews, giving examples of how some mentors imagined their future role and relationship:

Kind of having a supportive role a bit, uh, like being there even when there are uh, if there are sometimes difficult phases, and, let's say, being a bit of a launch pad. (Jovanovic, lines 80-82)

Something like uh, a fixed point. Something that's simply there. (Steiner, line 123)

This fact, i.e., the depiction and understanding of this core task of being a mentor for an URM, surprised us initially, at least against the overall image, which portrayed these young people as a highly discriminated social group with potentially enhanced professional needs. However, from a loose coupling perspective, making out 
something this unclear to be a clear idea shows that the training provided future mentors with a particular certainty of what mentoring was about-including themselves and the other(ed). This "certain uncertainty" and "determined indetermination", as I would like to call it, was strongly connected to the enhancement of volunteers' biographical reflexivity. It offered them the freedom to later adapt their own behaviour to suit perceived necessities and needs in their personal mentoring relationship. Perhaps strict indications of "what to do" would have impacted negatively on volunteers' functionality regarding their "inner life", e.g., their personal life. It would probably have diminished volunteers' capacity to react to indeterminable tasks. In a worst-case scenario, volunteers would have simply fled the battleground, as adults also used mentoring to work on their "personal life", thus also engaging in youth mentoring for their own sake (Raithelhuber, 2019b).

All things considered, the training-amongst other elements-countered the pervasive threat of the different elements drifting apart. Particularly regarding the fact that people who are "unknown" to each other at the start and who share average "cultural(ized)" images of URMs can have feelings of alienation and disconcertment, the programme disseminated particular ways of understanding mentoring (including one's own role and the identity of the other), of orienting oneself and acting as a mentor or mentee. At the heart of this was the establishment of "membership categorizations" (Fitzgerald \& Housley, 2015). These were varied and adaptable, sometimes intrinsically ambivalent, and allowed everyone involved to develop a personal relationship in a confusing situation. This was important, as none of the matched couples could fully know how they would learn to understand each other and what modus vivendi they would find in the long run. In other words, at least at the outset of turning local adults into "godparents for URMs" (Raithelhuber, 2018), the loose coupling of mentors (and mentees) was achieved by reducing mentoring complexity to particular topics during training and in the public representation of the programme. As I will show, this was compounded by a structuring and ritualization of mentoring steps, as well as other elements which helped to create the concrete illusion of "godparenthoods for URMs".

\subsection{Producing Shared Values as a Sticky Glue}

In the mentoring programme and in the training of volunteers, in particular, shared values were strongly established to bring about systemic integration. Hence, besides legitimizing mentoring, the programme also "produced" mentors through the establishment of a particular morality and expected forms of (inter-)action. This aspect is well known from research on human services as moral work (e.g., Hasenfeld, 2009; White, 2003), and also discussed critically in contributions on human(itarian) relief (Ticktin, 2014). In the given case, these legitimate and coercive ways of understanding the mentoring relationship and related obligation crystallize in the very naming of the overall mentoring programme as a sort of "godparenthood", as argued above. Adding to this, the ombuds-organization hosted a red carpet event in which the principal investigator and one voluntary researcher also participated as guests without a particular function. During a ceremony, mentors and mentees were awarded roses on stage for their engagement in the programme. There, again, a caring, intimate and warm-hearted picture was painted publicly and symbolically. Mentors' and mentees' names had been written on coloured, cut-out hearts and pegged to a long line, each tiny heart inscribed with the word "thanks". Mentor-mentee pairs were invited to a photo shoot, posing with their heads together in a golden, empty picture frame. Top political representatives acknowledged the programme in their welcoming address. Moreover, the competitive regional, national and European awards that the project had already won were exhibited in a shrine-like installation, while the event was enhanced by solemn live music.

In short, all of this supported the production and distribution of shared values amongst various stakeholders and actors in the mentoring programme. Most likely, this allowed much more durable links to be created between unequal elements than any other efforts to shape, influence and facilitate mentorship activities through leadership or control could have brought about (for a critique of this in the mentoring literature see Colley, 2003). It helped stabilize the understanding of mentors and mentees as a part of a larger project. Hence, it can be said that these values served as a glue to attach civic solidarity to the mentoring scheme.

\subsection{Creating, Selecting, Disconnecting and Distributing Knowledge}

As mentioned, the training for prospective "godparents" singled out trauma and health, dealing with cultural differences, legal procedures and the everyday life and needs of URMs, i.e., housing and social issues. A group learning environment allowed them to share their ideas, questions and biographical experiences. Forming a particular set of knowledge about "godparenthoods for URMs" was also supported by the production and administration of data. Volunteers also engaged actively in creating, disconnecting and distributing knowledge, not least by volunteering for narrative interviews with us. Notably, the ways volunteers managed the flow of knowledge displays characteristics of loose coupling. Adults selected information on themselves and their mentee, sometimes differentiating between knowledge from their "inside" experience (e.g., what they went through with their young match) and that on the "outside" (e.g., the public, the media, their kinship and neighbours). On some occasions, mentors let us researchers in on a secret, e.g., on the "real-life" story of their protégé or on other aspects which would socially and politi- 
cally create a problematic, awkward image of the young people in general or of the mentoring programme. This aspect can be termed "semiotic loose coupling" (Orton \& Weick, 1990, p. 209). In such a process, information from one system (in our case the real-life experience with the young refugee) is decoded, classified and recoded or encoded in a particular manner that allows the other constitutive element of mentoring (in our case public communication) to maintain the system's integrity and consistency.

\subsection{Creating "Godparenthood for URMs" as an Entity and Boundary Object}

Staff and mentors together also showcased examples of "successful" mentoring on other occasions. Mentors were literally put on stage. Now in the role of "experts", they publicly bore witness to the enriching experience (for the mentor) and the positive transformation process (on the part of the refugee). They testified to the deep family-like relationship established with a young protégé, thus also suggesting there was a particular means-end relationship in mentoring. These somewhat ambivalent aspects are noticeable in the following two sequences from our field notes on the course for prospective mentors (participant observation). In the first, a person, presented to the group as a role model, answers the question of what kind of tips he/she has for future "godparents":

It's important to offer them a relationship; to show interest in the other person and "take them in", explains [experienced mentor] word for word. "An interest in other cultures, not holding back, taking the leap". As they need a long-term relationship. "Wanting to help isn't the main priority". Altogether, it is a great enrichment: "Love develops", explains [experienced mentor] word for word. (Field note from mentor training, mentor A)

Yes, I can really recommend it to anyone who has time. If you have two hours' time for the refugees, you can do a lot for the refugees. It's nice to see when they start integrating. (Field note from mentor training, mentor B)

Bringing together the various elements and representing "godparenthood for URMs" in a manner that was both durable and topical called for more than a one-off event, such as the kick-off evening or the red carpet event described above. In this sense, the release of group photos on social media and in the press, demonstrating unity among the various stakeholders, can be seen as efforts to build an entity or image.

Summarising the above, by this means, "godparenthood for URMs" was made objectifiable and personalized through representations and "representatives" of mentors, young refugees in mentorship, govern- ment ministers, decision-makers in public administration, ombuds-staff, speakers from both national and international NGOs, not to forget researchers (i.e., the author of this article). Producing communicable data and consumable images of mentoring for young refugees helped create a particular entity and particular heterogeneity across the system. Different actors could refer to this without losing their own systemic autonomy. Developing this "boundary object" (Star, 2010) required symbolical work and involved giving the various elements material form in a physical and virtual space.

Up to this point, I have presented five out of the six previously announced key examples of how ambiguities and uncertainties were both dealt with and brought about processes of organizing "godparenthoods for URMs". They mark challenges within this mentoring system. These challenges had to be worked on to create an interdependency enabling rationality and indeterminacy to co-exist and, consequently, enabling the system to achieve distinctive capacities and performances. At heart, this was connected to a central task: bringing about particular relationships between a local adult volunteer (a mentor) and a young person (a mentee). Following up on this, the final key example reveals how the project stabilized unequal relationships amongst people who were previously unknown to each other, by creating a hybrid space. It is perhaps the clearest example of how rationality and indetermination were concomitantly taken into account when processing and structuring the civic solidarity initiative.

\subsection{Stabilizing Unequal Relationships amongst Strangers in a Hybrid Space}

As a way to deal with uncertainty and ambiguity in the initial phase of a mentoring relationship, a ritualizing framework was applied. It was organized concentrically around the first date at the agency, following the mentor training, which was simply called "the matching". Agency staff metaphorically referred to it as the "marrying" of the "godparent" and the "youngster". In the following quote, two agency workers share their experiences on these matching events:

Worker B: And what usually happens is that we simply say, OK, good, that before we fill out the agreement together, the two of them, first the godparents present themselves again to the young people....Then the young people also present something about themselves, introduce themselves....Though, if necessary, of course, we help. If we notice that, OK, good, one of them's got a bit stuck. Because sometimes the godparents get stuck, too. It's not only....I'll never forget how one [mentor] suddenly couldn't remember what she liked doing [worker A and interviewer laught].

Worker A: That's what some of the godparents said: now I'm like really nervous... 
Worker B: As if they were getting married or they really had a new job and were now getting to know their new employer, like, like you'd really notice it straight away. So, then we did help, with the documents too, a bit....And then both, then we ask both of them, OK, now you've got to know one another again. Introduced yourselves again, too....Can you imagine it? We ask the young people first and they say yes. We also ask the godparent, of course. If they both say yes, the two of them have the chance to talk to one another again a bit, while we simply fill in this note.

It comes clear how the agency workers themselves arranged the "matching" as a sort of wedding, assuming the role of a personal dating assistant and marriage registrar. In the youth mentoring literature, Pryce, Kelly and Guidone (2014, p. 427) hint that though matching seems to be a routine and highly valued activity of programmes, it is still poorly conceptualized and empirically investigated. Mainstream views on matching build on individualistic psychological theories (attractiveness, choice, etc.) and focus on individual people's characteristics. In contrast, an organizational perspective foregrounds enactment: what is performed, rather than the actors per se. As the quote indicates, in the case under investigation, "matching" activities prepared, induced, shaped, and stabilized insecure situations in which people who were unknown to each other could act as if they knew one another and understood what mentoring was, thus getting a chance to engage personally on unfamiliar terrain. Early information events for URMs already connected them to legitimate causes and needs. In turn, the young refugees were enabled to communicate this and elicit a reaction from the mentoring scheme. In turn, staff decoded and codified what they heard in individual counselling sessions from the adults and from the young refugees.

These different aspects make it clear how rationality was produced on all sides (what a mentoring match achieves, in general and in particular), in artful combination with indeterminacy (as no one really could know what it would be like). On the one hand, the training reassured participants that the agency would find the "right match", e.g., through personal assessment and data acquisition. Staff stated that people only failed to accept or immediately undid the proposed relationship in rare cases. On the other hand, mentors (and mentees) were symbolically equipped with what I call a "natural" decision-making power. For example, they were assured that the pairing depended on their approval (during or after the first meeting) and that they themselves would "feel" right away whether they matched or not, always having the right to say "no" without being dropped from the scheme. In addition, the ritualization of the first meeting and the role of the agency as a sort of warrantor, intermediary and (potential) arbiter was also underlined by introducing an artefact: a "contract" outlining the agreement for the mentoring relationship, as illustrated in the quote on the matching event. All parties signed it, each person was given a copy. This process provided not only basic data for communicating with each other, but often determined the availability, frequency and content of later non-assisted meetings.

In summary, the contract focused on controllable, imaginable and realizable activities in the midst of an as yet uncharted relationship. All of this this provides rich examples of how aspects of rhythmizing, temporalizing, determining and contouring were artfully developed to make mentorship and matching controllable and determinable at an early phase. In particular, this insight into procedure and timing also highlights the assistive role of both material and virtual artefacts in bringing about this kind of hybrid space (printed forms, data bases, contracts, certificates, profile images, and other items). Yet, what started out with a meeting to learn German once a week or leisure activities, connected to the image of "simply being there" described above, would later turn into more serious, delicate issues, as we know from our follow-up interviews with mentors and agency staff. Mentors ended up helping to prepare "their" young refugee for decisive interviews in asylum procedures. In some cases, mentors even invited their protégé to move into their household upon coming of age, thus avoiding their relocation to a remote refugee camp, i.e., mass accommodation for adults run under the basic welfare support scheme. One mentor even bought a flat so the young man could find affordable housing. In another case, volunteers scraped together several thousand euros to enable family reunification, providing "their" minor with funds to pre-finance DNA kinship tests in their country of origin.

\section{Summary and Discussion of Findings}

This article looked into a community-based youth mentoring programme for URMs grounded in a civic solidarity initiative in an Austrian region. Applying a loose coupling perspective to findings from a long-term case study highlighted dynamic and dialectic aspects.

\subsection{Findings on the Six Key Examples of Organizing in the Mentoring System for URMs}

The accelerated implementation of the programme took place in a historical situation: the "long summer of migration" in 2015. Based on the concept of loose coupling with its focus on organizations as "interpretative systems" (Orton \& Weick, 1990, p. 218), I showed how a regional ombuds-agency achieved a different form of sense-making. According to my analysis, ambiguity and insecurity called for a new interpretation of the problem at hand: the enormous increase in URM arrivals. Hence, a mere aggregation of information within the beaten tracks did not enable the situation to be dealt with viably. Thus, activities finally flowed into a new mentoring scheme with a target group characterized by the agency as "URMs". By doing all of this, the agency was able to proclaim to different audiences that different ways 
of helping to improve the situation of young people in public care was something "natural" and fully coherent with the agency's universalistic mission. As the first step towards future implementation, the agency developed a new training course for adult volunteers, as well as many other vehicles for structuring, processing and ordering (e.g., membership categorizations, matching rituals). These were used as add-ins which guided participants (mentors and the young people) and stakeholders towards the assumption that there was a logic to the programme. Thus, rationality was produced (e.g., the image of a clear means-end relation within mentoring) which was intrinsically tied to aspects of indetermination (e.g., an uncharted relationship and uncontrollable future activities between mentors and mentees). This enabled everyone-including the young people-to enact the mentoring programme in a specific way: a way that not only conduced to the distributed, but interdependent system of mentoring but also allowed volunteers and young mentees to act at their own behavioural and cognitive discretion (thus see Orton \& Weick, 1990, pp. 210-211).

The training was only one core means of organizing and structuring elements within a dynamic system with frayed, permeable boundaries. Building on the organizational perspective of loose coupling, the undeterminability of means-end relations in mentoring (understood as a human service) was also dealt with by installing the matching process at the very core of the programme. Here, again, insecurity on all sides, as well as unknowability about how a personal relationship could actually be brought about, were tackled in various ways. From such a viewpoint, I reconstructed matching as an extended interconnection of various elements, both spatially and temporally. They intersect in a ritually staged event (the first, assisted "dating"), but stretch well before and after this particular activity, potentially becoming de-institutionalized and transforming into something else in the long run. Hence, paralleling results on HSOs, this article revealed how this mentoring system was capable of bringing about a particular networked capacity by combining two supposedly opposing aspects: rationality and indetermination (see Wolff, 2010, p. 24). An organization of this kind does not simply lack the capacity to fully "rationalize" all relevant aspects, and thus leave aside anything that exceeds its capacity for control. Quite the contrary, as the case demonstrated: both aspects - rationality and indetermination-were artfully taken into consideration in the context of organizational processing and structuring. This opened up a practical corridor in which issues around young people differentially included as URMs could be dealt with by engaging adult volunteers from local civil society.

\subsection{The Organizational Perspective of "Loose Coupling" as a Heuristic to Address Complexity}

Following my analysis, mentoring in the form of "godparenthood for URMs" most likely became "successful" and even sustainable in the example because it offered an institutional model for both dealing with and producing uncertainty and ambiguity in an artful way. This allowed core actors in the programme (mentors, youth) to make sense of the confusing situation-including by structuring uncertainty and ambiguity all the way down to a personal, physical, emotional level (on these aspects in "sponsorships" or "godparenthoods for URMs" in Austria, see Scheibelhofer, 2019). On an abstract and general level, it stands to reason that civic support became mainstreamed as mentoring precisely because relationships amongst various distributed elements could be built up in a flexible yet determined manner. At the peak of multiplied acts of solidarity with refugees in 2015 , various means were invented of allowing people to take up such relationships (see Feischmidt et al., 2019). However, there is reason to assume that the institutionalization of "godparenthoods for URMs" offered options for integrating various elements in a way that was potentially more "effective" than other relationships between strangers. It did so partly in a pedagogical manner by using socio-cultural(ized) images of "godparents" and "URMs" (Raithelhuber, 2018), which were taken up by mentors and mentees alike (Raithelhuber, 2019a, 2019b). This model emerged and has subsisted until now because it was financially viable, projectable, advertizable, administrable and manageable for a variety of actors under the given circumstances, including the youth welfare authorities (see subsection 7.1 below).

Using Weick's "loose coupling" perspective allowed me to register the complexity, dynamics and dialectics involved in organizing "godparenthoods for URMs" in a way that goes beyond a widespread neo-institutionalist understanding of the "coupling" of (organizational) structure and environment (for a critique see Wolff, 2010, p. 308). For example, the study by von Oppen (2018), mentioned earlier, observed ambivalences within a particular HSO; a group home for URMs in child and youth care in Germany. Drawing on a neo-institutionalist approach, von Oppen (2018, pp. 185-187) merely mapped perceived ambivalences in the use of cultural(ized) images of URMs in a dichotomous manner, i.e., as contradictions. Therefore, he interpreted them as a sort of "decoupling" of the formal structure from everyday institutional practice and routine. This approach implies that, for strategic reasons, the cultural representations which are used for justification towards the outside world need to be strictly separated from the interpretations made by professionals in day-to-day care work with URMs. In my view, what is problematic about this approach is that it turns coupling issues into an either-or question (either closely or loosely coupled). However, in this kind of attempt to get rid of the ambiguity found in our material, we as researchers might end up with a weak understanding of events. In contrast to this, my case study provides a more fine-grained picture of how organizing was pursued mindfully "in the face of ambiguity" (Weick, 2015, p. 122). To give some insight into this, the present 
article started out from the various ways that sensemaking was achieved by the ombuds-agency in the light of particular incidents. In the given case, these were the increased arrival of URMs in 2015, the mentors of the established mentoring programme seeking advice at the ombuds-agency and so forth. Hence, the ambiguity present was turned into both a universalistic understanding of the issues at hand (i.e., URMs' neglected rights as children) and a particularistic approach (i.e., focusing on how URMs were different in terms of their legal status, social needs and culture). Later on, when something this unclear was made out to be a clear idea (i.e., the task of a mentor as "simply being there"), one could say that the ambiguity was increased. However, while it was heightened, at the same time ambiguity was grasped at a workable level and in a transient manner, i.e., in a way that allowed a next provisional step to be taken (see Weick, 2015, p. 117) and upcoming experiences to be integrated-including by the mentors and the young people themselves.

"Godparenthood for URMs" can be seen as a negotiated arena in which a number of different actors jointly ascertained that mentoring should be established to treat URMs as a "social problem". These interconnections evolved precisely because they offered everyone (or at least many people) advantages if they did (not) take particular decisions, (not) engage in something, and so forth. This evolution, however, required some element within the overall mentoring system to take on the role of a controller (signalling the transgression of boundaries), of surety (e.g., by symbolically guaranteeing the cohesion of independent actors), of immediate responsiveness (e.g., by intervening as a rescue unit in an emergency), etc. Therefore, on a surface level, the role of the ombuds-agency seems to stand out. However, to counter the threat of reification it needs to be acknowledged that no organization has a (fixed and enduring) capacity to bring about something that "works" and is "effective" and "prize-winning". Quite the contrary to this kind of essentialist agentic idea, various elements became loosely coupled into what we perceived as "godparenthoods for URMs". Seen this way, each of the elements within the system had partial knowledge of and interconnection with the overall, complex aspects involved, e.g., the everyday life of the young refugees or the bureaucratic procedures within the matching agency. Yet all of them jointly constructed a representation of "godparenthood for URMs" as a "boundary object" (Star, 2010). They produced an image that fed back into these elements, outstripping the capacities of each individual element to reflect, determine and represent the multitude of events involved in mentoring (see Weick, 2005, p. 54). This might be the pivot which has prevented the mentoring project under observation from drifting apart until now, as has happened to many initiatives for refugees arising in 2015.

Regarding the contribution of this example for future research, within a broader picture, I would venture to say that this organizational perspective has added complexity in understanding the emergence and working of refugee support initiatives, in particular as it did not start out by sharply contrasting state actors with non-state actors, as is often the case in this field (for Austria see De Jong \& Ataç, 2017). My proposal is that the present example suggests that this specific organizational approach of loose coupling within systems could be used in future studies to deal with questions which are currently driving academic debate on refugee support initiatives, in order to better understand and assess related institutional and structural developments.

\section{Conclusion and Outlook: A "Political" Assessment}

If the intention of this article were only to fulfil the two objectives indicated, it would have to stop right here. I have already come to a conclusion on empirical findings, by looking at a particular initiative for young refugees through the lens of the concept of "loose coupling". However, at the beginning, I also argued that this organizational perspective on civic solidarity in refugee protection would provide a better viewpoint for assessing what has been produced and has become organizable and producible within these initiatives with regard to more contentious political dimensions. To be able to do so, I introduced the concept of "differential inclusion" from critical migration and border studies. Now, finally, I return to this view and try to give an answer to these "political" questions. Has this civic support initiative resulted in more structural cultural and political changes? Have the mentoring programme and all the effort that citizens put into it enabled public administrators and politicians to uphold the differential inclusion of "unaccompanied minor aliens"? Or have "godparenthoods for URMs" brought about a progressive shift? As I stated at the outset, I would certainly venture to say that this form of civic solidarity and volunteering has extended established, professional and institutionalized welfarist social support and care, rearranging the differential inclusion of these young people-with mixed results.

\section{1. "Godparenthoods for URMs" as a Modernization of Differential Inclusion}

My assessment is that on a political level, the "godparenthood" programme based on orchestrated civic solidarity did not turn around the general institutional attitude towards these young people. This, however, is hardly surprising given the overall political climate. Shortly before the programme started, a new piece of legislation was drafted in the province in question, codifying the exclusion of minor asylum claimants from child and youth welfare. While this formulation was eventually cancelled (as it was obviously anti-constitutional and violated the UN CRC), it mirrors exactly how welfare institutions have acted to date. Public authorities, even those with a selfproclaimed humanitarian stance towards refugees, have 
used the initiative from the very beginning to support discriminatory policies. To give but one example, when the first "godparenthood" became a "host family" (remember that this was intended for a few cases as a sort of "top-up" to existing mentorships), the minister for social affairs and integration posted on Facebook:

Possible at last-Minister Wagner [responsible for youth welfare; the author] has got it through: unaccompanied refugee minors in \#Karlstadt can now be cared for in host families (similar to foster families). Thanks to [ombuds-organization].

A person obviously protesting against this development of a special scheme of "host families" instead of using "foster families" under the appropriate legislation for out-of-home care, i.e., the Child and Youth Welfare Act, commented:

Why not in foster families??? They're also children and adolescents under the JWG [Youth Welfare Act], aren't they?!

The minister for social affairs and integration responded:

Because asylum-seeking children/young people have a different status and the host parents also need special training (intercultural competence, knowledge about their cultures of origin).

This is just one example showing that concepts which the mentoring programme made relevant (e.g., specialist knowledge on cultural issues) enabled public authorities and administration to rationalize their differential inclusion of URMs, leaving these young people with severely reduced life chances. I indicated at the outset that manifold actors, including the ombuds-agency under observation, condemned the institutionalized ways of dealing with these young people as "URMs" as a form of (il)legal discrimination. Given that this applies almost exclusively to non-European, non-Western youth from former colonies, now ridden with conflict and (proxy) wars, discrimination is ultimately racist, in my opinion. Seen this way, the mentoring programme "helped" public authorities to treat a political issue of (il)legal inequality predominantly as a pedagogical issue of differentiated public care and youth services and simultaneously as an issue of civic solidarity. This is what I coin the "modernization of differential inclusion". It falls in line with other efforts proliferating "techniques and technologies of control within broader logics of governmentality and management" (De Genova et al., 2014, p. 3).

\section{2. "Godparenthoods" as a Road to "Subversive Humanitarianism"?}

If we look at the current status of the programme, it is still a pilot scheme. The original intention was to con- vince politicians and authorities in child and youth welfare to transform the programme into a tax-financed, regular social service delivered by a private welfare organization. However, many factors have changed since its launch in 2015. Arrivals of URMs have almost abated and many of the remaining young refugees have "aged out". There has been a turn towards right-wing extremist governments with barely hidden fascist traits. The institutional discrimination of (young) refugees has been hardening. Their asylum claims are more often treated arbitrarily, and even "safe" statuses are revoked. Hence, in the eyes of agency staff, the possibility to institutionalize mentoring beyond its provisional status is fading away. The number of recruits has dropped.

The number of godparents, however, was still stable at the end of 2018. Some of them are already engaging in a "second round" with a new youngster. They see themselves as core stabilizing factors in the life of the young people, and so do their mentees. In several followup interviews, mentors explained that these young people would not have had any chance or at least would have been unable to aspire to and achieve what they wanted (an average life in the receiving country), if they had not been able to rely on their mentors' support. This view was supported by young refugees in our multilingual group interviews (Raithelhuber, 2019a). Mentors motivate the young people to keep going when facing an asylum interview or receiving a negative decision. Mentors drive them to invest even more, to be able to get some "proof" of their integration efforts which can be presented to the asylum agency, in the hope that this will avoid deportation. What is more, in follow-up interviews, adult volunteers related that they experienced their "own" society side by side with their young match in an unprecedented manner, raising their political awareness. Such experiences can reach beyond current, established forms of subjection and subjectivity. Potentially, they imply forms of "subversive humanitarianism" (Vandevoordt \& Verschraegen, 2019) and of a "politicization of charity" (Feischmidt \& Zakariás, 2019) which may crystallize into more contentious political figurations one day (thus see Scheibelhofer, 2019). Those who have recently shown interest explain that by volunteering they want to set a counterpoint to the current national government, as they consider this target group of (young) refugees as one that has come under fire, in particular.

Moreover, the ombuds-organization believes itself to be an anchor point for young refugees in the region. Due to the sustained shortage of mentors, hundreds on the list might never be assigned to a "godparent". However, some of these long-term candidates utilize agency staff to get advice, to deal with legal issues or to search for housing. Hence, the programme itself has turned into a reliable companion in the midst of the biographical, social and spatial movements in refugees' life courses. And, last but not least, in the view of the agency, the relations to both volunteers and young refugees have brought these young people's lived realities very close to them, 
putting their unbearable intricacies right on their desks. The agency takes up many of these young refugees in and around the mentoring programme as particular "cases". They provide extended support, e.g. by facilitating family reunification, intervening in forced returns, or organizing free legal defence. I venture to say that if these local adults were not there and if staff members did not work with them and their mentees, there would often simply be nobody there to protect these young people against infringements, including by state authorities.

\subsection{The Need for Further Research at the Intersection of (Im)Mobilities and (De)Protection}

Considering these findings in a broader context, the mentoring scheme can be seen as one that works at the intersection of (im)mobilities and (de)protection (see Raithelhuber et al., 2018) in a productive, but also ambivalent way. The study has unveiled structures which need to be explored not only in research, but also in practice; in social work and (refugee) activism. Concerning a political assessment, we should investigate even more how access to protection and even the notions of membership, rights and entitlements are changing practically, and how research can foster this in a practical-utopian way. This includes looking at ideas of sociality or commonality that are connected with practices-however ambivalent and problematic we consider such ideas at first sight with regard to issues of equality, universalism and political contention. It is evident that a more nuanced discussion and sustained engagement are needed. Clearly, a sophisticated assessment of a civic initiative cannot simply build on a binary scheme of (conservative and problematic) humanitarian activity on the one hand and (progressive) political activity on the other hand. We should not easily fall into the trap of a dualistic "either-or" assessment of these matters: either reproduction and reaffirmation of power structures and refugeeism through (humanitarian) protection initiatives or subversion and the transformation of exclusionary logics, subjectivities and practices (e.g., with regard to sanctuary practices, see Lippert \& Rehaag, 2013). The final quote below makes this clear. In a recent interview, looking back on more than three years of work, a staff member assessed the current role of mentoring for URMs as follows. He/she refers particularly to young people threatened with the withdrawal of their refugee status:

OK, on the other hand, there are also cases where the young people...are just so firmly embedded, where I think the BfA [Federal Office for Immigration and Asylum] won't dare pull them out....But actually, they do pluck up the nerve occasionally. There are just some cases when I think, good for them, this development is simply spot on. The thing is, I think for some we've simply also become friends. (Interview with ombuds-staff B)

\section{Acknowledgments}

I owe particular thanks to Stephan Wolff for his comments during a data analysis session, as well as to my fellow researchers Kübra Çağlar, Maria-Amancay Jenny, Hila Kakar and Doris Reithmaier, and all participants in the study.

\section{Conflict of Interests}

The author declares no conflict of interests.

\section{References}

Anderson, B. (2013). Us and them? The dangerous politics of immigration control. Oxford: Oxford University Press.

Balibar, É. (2003). We, the people of Europe? Reflections on transnational citizenship. Princeton, NJ: Princeton University Press.

Bassermann, M.-A., \& Spiegelfeld, A. (2018). Unaccompanied minors following status determination in Austria. Vienna: International Organization for Migration, Country Office in Austria.

Behnia, B. (2007). An exploratory study of befriending programs with refugees: The perspective of volunteer organizations. Journal of Immigrant \& Refugee Studies, 5(3), 1-19.

Birman, D., \& Morland, L. (2014). Immigrant and refugee youth. In D. L. DuBois \& M. J. Karcher (Eds.), Handbook of youth mentoring (2nd ed., pp. 355-368). Los Angeles, CA: SAGE.

Colley, H. (2003). Mentoring for social inclusion: A critical approach to nurturing mentor relationships. London: RoutledgeFalmer.

Czarniawska, B. (2006). A golden braid: Allport, Goffman, Weick. Organization Studies, 27, 1661-1674.

De Genova, N., Mezzadra, S., \& Pickles, J. (2014). New keywords: Migration and borders. Cultural Studies, $29,55-87$.

De Jong, S., \& Ataç, I. (2017). Demand and deliver: Refugee support organisations in Austria. Social Inclusion, 5, 28-37.

Die Kinder- und Jugendanwaltschaften. (2015). Kinder ohne Rechte. Positionspapier zur Situation der unbegleiteten minderjährigen Flüchtlinge. Juni 2015 [Children without rights. Position paper on the situation of unaccompanied refugee minors. June 2015]. Vienna: Die Kinder- und Jugendanwaltschaften Österreichs. Retrieved from http://www.kija.at/images/ 2015_06_15_Positionspapier_zum_ Weltfluechtlingstag_2015.pdf

Emerson, R. M., Fretz, R. I., \& Shaw, L. L. (2011). Writing ethnographic fieldnotes ( 2 nd ed.). Chicago, IL: The University of Chicago Press.

Feischmidt, M., Pries, L., \& Cantat, C. (Eds.). (2019). Refugee protection and civil society in Europe. Cham: Springer International Publishing. 
Feischmidt, M., \& Zakariás, I. (2019). Politics of care and compassion: Civic help for refugees and its political implications in Hungary: A mixed-methods approach. In M. Feischmidt, L. Pries, \& C. Cantat (Eds.), Refugee protection and civil society in Europe (pp. 59-100). Cham: Springer International Publishing.

Fitzgerald, R., \& Housley, W. (Eds.). (2015). Advances in membership categorisation analysis. London: SAGE.

Ganner, M., Jicha, S., \& Weber, K. (2016). Gutachten zu Rechtsproblemen von SOS-Kinderdorf-Österreich mit unbegleiteten minderjährigen Flüchtlingen [Report on legal problems of SOS Children's Village, Austria with unaccompanied refugee minors]. Innsbruck: Universität Innsbruck.

Glick Schiller, N., \& Salazar, N. B. (2013). Regimes of mobility across the globe. Journal of Ethnic and Migration Studies, 39(2), 183-200.

Hasenfeld, Y. (2009). The attributes of human service organisation. In Y. Hasenfeld (Ed.), Human services as complex organizations (pp. 9-32). Los Angeles, CA: SAGE.

Heilemann, S. (2017). The accommodation and care system for unaccompanied minors in Austria. Social Work \& Society, 15(1).

Lace, A. (Ed.). (2018). Newcomer Integration in Europe: Best practices and innovations in response to 2015. Brussels: Forum for European Progressive Studies.

Lakind, D., Atkins, M., \& Eddy, J. M. (2015). Youth mentoring relationships in context: Mentor perceptions of youth, environment, and the mentor role. Children and Youth Services Review, 53, 52-60.

Larsson, M., Pettersson, C., Eriksson, C., \& Skoog, T. (2016). Initial motives and organizational context enabling female mentors' engagement in formal mentoring A qualitative study from the mentors' perspective. Children and Youth Services Review, 71, 17-26.

Lippert, R. K., \& Rehaag, S. (2013). Introduction: Sanctuary across countries, institutions, and disciplines. In R. K. Lippert \& S. Rehaag (Eds.), Sanctuary practices in international perspectives: Migration, citizenship and social movements (pp. 1-12). New York, NY: Routledge.

Merhaut, N., \& Stern, V. (2018). Asylum policies and protests in Austria. In S. Rosenberger, V. Stern, \& N. Merhaut (Eds.), Protest movements in asylum and deportation (pp. 29-48). Cham: Springer International Publishing.

Meyer, J. W. (2017). Afterword: Fragmented organizations in the society of organizations. In G. Krücken, C. Mazza, R. Meyer, \& P. Walgenbach (Eds.), New themes in institutional analysis. Cheltenham: Edward Elgar Publishing.

Mezzadra, S., \& Neilson, B. (2012). Borderscapes of differential inclusion: Subjectivity and struggles on the threshold of justice's excess. In E. Balibar, S. Mezzadra, \& R. Samaddar (Eds.), Politics, history, and social change. The borders of justice (pp. 181-203). Philadelphia, PA: Temple University Press.
Nail, T. (2015). The figure of the migrant. Stanford, CA: Stanford University Press.

Nohl, A.-M. (2010). Narrative interview and documentary interpretation. In R. Bohnsack, N. Pfaff, \& W. Weller (Eds.), Qualitative analysis and documentary method in international educational research (pp. 195-2018). Opladen: Budrich.

Orton, J. D., \& Weick, K. E. (1990). Loosely coupled systems: A reconceptualization. The Academy of Management Review, 15, 203-223.

Pryce, J., Kelly, M. S., \& Guidone, S. R. (2014). Mentor and youth matching. In D. L. DuBois \& M. J. Karcher (Eds.), Handbook of youth mentoring (2nd ed., pp. 427-438). Los Angeles, CA: SAGE.

Raithelhuber, E. (2018). How "godparents" are made for "unaccompanied refugee minors": An ethnographic view into the training of future youth mentors. Child \& Youth Services, 39(4), 250-283.

Raithelhuber, E. (2019a). 'If we want, they help us in any way': How 'unaccompanied refugee minors' experience mentoring relationships. Manuscript submitted for publication.

Raithelhuber, E. (2019b). Turning into a "godparent". How adult volunteers negotiate their personal life to become a mentor for "unaccompanied refugee minors". Manuscript submitted for publication.

Raithelhuber, E., Sharma, N., \& Schröer, W. (2018). The intersection of social protection and mobilities: $A$ move towards a 'practical utopia' research agenda. Mobilities, 13(5), 685-701.

Scheibelhofer, P. (2019). Gender and intimate solidarity in refugee-sponsorships of unaccompanied young men. In M. Feischmidt, L. Pries, \& C. Cantat (Eds.), Refugee protection and civil society in Europe (pp. 193-219). Cham: Springer International Publishing.

Schott-Leser, H. (2018). Ehrenamt im Kontext von Flucht und Marginalisierung: Eine Untersuchung pädagogischer Laientätigkeit auf Basis von Patenschaftsbeziehungen mit Jugendlichen in prekären Lebenslagen [Volunteering in the context of refugeeism and marginalisation: An investigation of educational laypeople's activities based on godparentships with young people in precarious situations in life]. Opladen: Barbara Budrich.

Star, S. L. (2010). This is not a boundary object: Reflections on the origin of a concept. Science, Technology, \& Human Values, 35, 601-617.

Sulimani-Aidan, Y., Melkman, E., \& Hellman, C. M. (2019). Nurturing the hope of youth in care: The contribution of mentoring. The American Journal of Orthopsychiatry, 89(2), 134-143.

Ticktin, M. (2014). Transnational humanitarianism. Annual Review of Anthropology, 43, 273-289.

UNHCR. (2018). Rechtsvertretung von unbegleiteten Kindern und Jugendlichen im Asylverfahren [Legal representation of unaccompanied children and young people in the asylum process]. Vienna: UNHCR Österreich. 
Vandevoordt, R., \& Verschraegen, G. (2019). Subversive humanitarianism and its challenges: Notes on the political ambiguities of civil refugee support. In M. Feischmidt, L. Pries, \& C. Cantat (Eds.), Refugee protection and civil society in Europe (pp. 101-128). New York, NY: Palgrave Macmillan.

Von Oppen, J. (2018). Flucht, Migration und pädagogische Organisationen: Zur Bedeutung von kultureller Differenz in der Sozialen Arbeit mit unbegleiteten minderjährigen Geflüchteten [Flight, migration and educational organisations: On the significance of cultural difference in social work with unaccompanied refugee minors]. Weinheim: Beltz Juventa.

Weick, K. E. (1976). Educational organizations as loosely coupled systems. Administrative Science Quarterly, 21, 1-19.

Weick, K. E. (2005). Managing the unexpected: Complexity as distributed sensemaking. In R. R. MacDaniel \& D. J. Driebe (Eds.), Uncertainty and surprise in complex systems: Questions on working with the unex- pected (pp. 51-65). Berlin: Springer.

Weick, K. E. (2015). Ambiguity as grasp: The reworking of sense. Journal of Contingencies and Crisis Management, 23(2), 117-123.

White, S. (2003). The social worker as moral judge. Blame, responsibility and case formation. In C. Hall, K. Juhila, N. Parton, \& T. Pöso (Eds.), Constructing clienthood in social work and human services (pp. 177-192). London: Jessica Kingsley Publishers.

Wolff, S. (2010). Soziale personenbezogene Dienstleistungsorganisationen als lose gekoppelte Systeme und organisierte Anarchien [Personal social service organisations as loosely coupled systems and organised forms of anarchy]. In T. Klatetzki (Ed.), Soziale personenbezogene DienstleistungsorganisationenSoziologische Perspektiven [Personal social service organisations: Sociological perspectives] (pp. 285-335). Wiesbaden: VS Verlag für Sozialwissenschaften.

\section{About the Author}

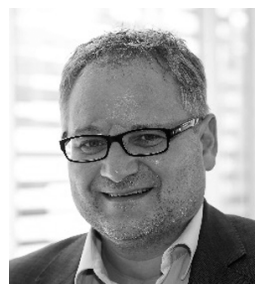

Eberhard Raithelhuber (PhD) is a Social Scientist with a special focus on social work and social pedagogy, currently based at the Department of Educational Science, University of Salzburg, Austria. His research projects are located at the intersection of child and youth services, migration and mobilities, and social policy and welfare. He has published on transitions in the life course, agency, social support and intervention, youth and young adults, regional development and networks, citizenship and democracy, and transnationalism. 